\title{
ОЦЕНКА РЕГИОНАЛЬНОЙ СИСТЕМЫ ЗДРАВООХРАНЕНИЯ И ОБОСНОВАНИЕ ВНЕДРЕНИЯ ФИНАНСОВОГО ОБЕСПЕЧЕНИЯ МЕДИЦИНСКОЙ ПОМОЩИ НА ПРИНЦИПАХ ФОНДОДЕРЖАНИЯ
}

\author{
(C) 2021 Качкова Ольга Евгеньевна \\ кандидат экономических наук, доцент, \\ заместитель руководителя Департамента аудита и корпоративной отчетности \\ Финансовый университет при Правительстве Российской Федерации, Россия, Москва \\ https://orcid.org/0000-0003-1439-2845 \\ (c) 2021 Кришталева Таисия Ивановна \\ доктор экономических наук, профессор Департамента аудита и корпоративной отчетности \\ Финансовый университет при Правительстве Российской Федерации, Россия, Москва \\ https://orcid.org/0000-0003-4297-5917
}

В статье рассмотрены подходы к оценке региональных показателей эффективности функционирования системы здравоохранения для выработки предложений по внедрению новых форм финансового обеспечения медицинской помощи на принципах фондодержания (на примере Московской области).

Ключевые слова: Фондодержание, медико-демографические ситуации, ресурсная обеспеченность, заболеваемость населения, оплата медицинской помощи.

Для повышения доступности медицинской помощи в условиях фондодержания необходимо обеспечить реальное право гражданина на выбор медицинской организации, на фоне расширения информирования граждан о деятельности медицинских организаций. Пациент должен перейти от неинформированного просителя медицинской помощи к информированному потребителю. Рейтинг медицинских организаций по показателям доступности и качества оказания медицинской помощи является важным условием реализации права гражданина на выбор медицинской организации [7, С. 41].

Предоставить медицинским организациям финансовую автономию на основе модели конечных результатов деятельности и взаиморасчетов с исполнителями медицинских услуг сможет модель фондодержания. В распоряжении медицинской организации фондодержателя должны оставаться те финансовые средства, которые были сэкономлены в ходе процесса использования действенных технологий по диагностике, лечению и реабилитации пациентов.

Фондодержание позволит создать пациенториентированную модель в системе ОМС, обеспечивающую осознанный выбор медицинской организации и доступность медицинских услуг для застрахованных, а медицинским организациям мотивированность к внедрению ресурсосберегающих технологий, обеспечивающих массовую профилактику заболеваний, эффективную реабилитацию и качественную медицинскую помощь [15, С. 193].

Учитывая низкую эффективность модели финансирования, основанной на простой подушевой оплате и реализуемой в настоящее время в большинстве субъектов Российской Федерации, представляется целесообразным провести более детальный анализ показателей деятельности региональных систем здравоохранения, демонстрирующих необходимость совершенствования организационно-управленческих подходов к формированию государственного задания на оказание медицинской помощи, распределению объемов медицинской помощи по видам, формам и условиям ее оказания, механизмам и порядкам взаимодействия медицинских организаций, реализующих территориальные программы государственных гарантий бесплатного оказания гражданам медицинской помощи, а также принципам финансового обеспечения данных мероприятий [3, С.47].

Наиболее изученным и показательным регионом для данного исследования с последующей апробацией предложений является Московская область по следующим причинам: 
1. Региональная модель финансирования ПМСП с элементами использования фондодержания имела успешный опыт применения в 2005-2006 годах и должна была получить продолжение при наличии соответствующего финансирования и четких механизмов взаимодействия между медицинскими организациями-фондодержателями и иными медицинскими учреждениями, оказывающими скорую, в том числе скорую специализированную, и специализированную медицинскую помощь пациентам, доработки отдельных критериев и показателей эффективности работы первичного звена здравоохранения, как главного распорядителя финансовых средств, а также при совершенствовании нормативно-правового регулирования способов оплаты за оказанную медицинскую помощь.

2. Система здравоохранения Московской области испытывает повышенное давление со стороны соседних регионов, выраженное в оттоке медицинских кадров в г. Москву (по причине более привлекательных условий труда) при одновременном росте численности обслуживаемого населения за счет миграционных процессов (в т.ч. за счет притока населения из соседних регионов). Данные обстоятельства усугубляют ситуацию с диспропорцией медицинских кадров в первичном звене здравоохранения и в стационаре, приводят к дисбалансу в ресурсном обеспечении, обуславливая необходимость поиска новых механизмов создания мотивации у медицинских работников, прежде всего финансовой, к осуществлению трудовой деятельности в данном регионе.

3. Текущая медико-демографическая ситуация в регионе при существующей ресурсной базе системы здравоохранения, смещенных акцентах на стационарное звено здравоохранения, подходах к финансовому обеспечению оказания медицинской помощи, а также результаты оценки удовлетворенности населения качеством и доступностью медицинской помощи свидетельствуют о необходимости ее серьезной трансформации и перенастройки [6, С. 38].

Для оценки необходимости проведения структурных преобразований в системе здравоохранения региона, требующих, в том числе, концептуально новых подходов к организации оказания медицинской помощи, формированию преемственности на всех этапах, финансовому обеспечению для эффективного взаимо- действия медицинских организаций, требуется детальный многокомпонентный анализ следующих параметров:

- медико-демографической ситуации;

- ресурсной обеспеченности;

- модели планирования и оплаты медицинской помощи в рамках региональной программы OMC;

- объемов потребления медицинской помощи в разрезе условий ее оказания;

- степени удовлетворенности населения качеством и доступностью медицинской помощи [4].

Общая численность населения Московской области на 1 января 2020 года по данным Росстата составляет 7690863 человек, при этом городское население - 6258082 человек, или 81,4\% от всего населения, сельское - 1432781 человек, или $18,6 \%$.

Доля населения старше трудоспособного возраста (женщины 55 лет и старше, мужчины 60 лет и старше) в Московской области составляет 25,1\%, в Российской Федерации - 25,9\%, тогда как доля детей (0-15 лет) в Московской области - 18\%, в Российской Федерации - 18,7\%. Эти данные свидетельствуют о пожилом составе населения и формируют низкие показатели рождаемости и высокие показатели смертности населения Московской области [9].

Следует отметить стойкую тенденцию к росту доли лиц старше трудоспособного возраста, так, в 2012 году на данную возрастную группу приходилось 23,9\%, а в 2019 году - 25,1\%, при снижении доли лиц трудоспособного возраста за данный период с 61,6 до 57\%. На долю мужчин в общей структуре населения приходится 46,3\%, на женщин - 53,7\% (в Российской Федерации соответственно 46,4\% и 53,6\%). В результате наличия значительной доли пожилого населения и уменьшения доли лиц репродуктивного возраста уровень рождаемости имеет тенденцию к снижению и составляет 11 на 1000 населения в 2018 году (в Российской Федерации - 10,9\%). За 2019 год уровень рождаемости составил - 9,5 на 1000 населения (соответственно в Российской Федерации - 10,1\%). Суммарный коэффициент рождаемости (число детей, приходящихся на одну женщину) в Московской области составляет 1,528 (в Российской Федерации - 1,57), к 2024 году планируемое значение данного показателя $-1,730$, в соответствии с национальным проектом «Демография». 
В 2019 году естественная убыль населения равнялась $-2,5$ на 1000 населения (в Российской Федерации естественная убыль составила $-2,2)$.

Ожидаемая продолжительности жизни (ОПЖ) за 2019 год в Московской области на 0,6 года выше среднероссийского значения и составляет 73,9 года (Российская Федерация $-73,3$ лет).

Показатели первичной заболеваемости населения Московской области в 2018 году на 9,7\% ниже, чем в Российской Федерации и на 0,3\% больше, чем в ЦФО.

В структуре первичной заболеваемости первое место занимают болезни органов дыхания, на которые приходится 49,4\%, при этом у детей $-70,2 \%$, у лиц старше трудоспособного возраста - 32,8\%, данные представлены в таблице 1.

У детей на втором месте находятся травмы и отравления, которые составляют 6\%, далее следуют болезни кожи и подкожной клетчатки $4,8 \%$ и инфекционные заболевания $-3,6 \%$ [1].

У лиц трудоспособного возраста на втором месте травмы и отравления - $16,2 \%$, третье место занимают болезни кожи и подкожной клетчатки $-7,5 \%$, далее следуют болезни системы кровообращения $-6 \%$, мочеполовой системы $5,9 \%$ и болезни костно-мышечной системы и соединительной ткани $-4,8 \%$.

Второе место в структуре первичной заболеваемости лиц старше трудоспособного возраста занимают травмы и отравления $-13,9 \%$, третье место - болезни системы кровообращения $10,6 \%$, затем следуют болезни кожи и подкожной клетчатки $-7,5 \%$ и болезни костно-мышечной системы и соединительной ткани - $6 \%$.

Уровень общей заболеваемости (острые за-

Таблица 1. Общая заболеваемость населения различных возрастных групп Московской области и структура, 2018 г. [9].

\begin{tabular}{|c|c|c|c|c|c|c|c|c|}
\hline \multirow[t]{2}{*}{ Название классов } & \multicolumn{2}{|c|}{$\begin{array}{c}\text { Общая заболе- } \\
\text { ваемость } \\
\text { Все население }\end{array}$} & \multicolumn{2}{|c|}{$\begin{array}{l}\text { Дети } \\
0-14\end{array}$} & \multicolumn{2}{|c|}{$\begin{array}{l}\text { Взрослое насе- } \\
\text { ление }\end{array}$} & \multicolumn{2}{|c|}{$\begin{array}{l}\text { Старше тру- } \\
\text { доспособного } \\
\text { населения }\end{array}$} \\
\hline & $\begin{array}{c}\mathrm{Ha} \\
1000\end{array}$ & $\%$ & $\begin{array}{c}\mathrm{Ha} \\
1000\end{array}$ & $\%$ & $\begin{array}{c}\mathrm{Ha} \\
1000\end{array}$ & $\%$ & $\begin{array}{c}\mathrm{Ha} \\
1000\end{array}$ & $\%$ \\
\hline $\begin{array}{l}\text { Зарегистрировано заболеваний - } \\
\text { всего }\end{array}$ & 1331,3 & 100,0 & 1816,8 & 100,0 & 1208,0 & 100 & 1605,0 & 100,0 \\
\hline $\begin{array}{l}\text { Инфекционные и паразитарные } \\
\text { болезни }\end{array}$ & 36,7 & 2,8 & 60,7 & 3,3 & 31,6 & 2,6 & 22,7 & 1,4 \\
\hline Новообразования & 49,3 & 3,7 & 9,5 & 0,5 & 58,7 & 4,9 & 108,2 & 6,7 \\
\hline Болезни крови, кроветворных органов & 5,5 & 0,4 & 8,4 & 0,5 & 4,9 & 0,4 & 5,4 & 0,3 \\
\hline $\begin{array}{l}\text { Болезни эндокринной системы, } \\
\text { расстройства питания и нарушения } \\
\text { обмена веществ }\end{array}$ & 64,0 & 4,8 & 22,5 & 1,2 & 72,7 & 6,0 & 144,1 & 9,0 \\
\hline $\begin{array}{l}\text { Психические расстройства и рас- } \\
\text { стройства поведения }\end{array}$ & 40,4 & 3,0 & 24,2 & 1,3 & 43,5 & 3,6 & 38,1 & 2,4 \\
\hline Болезни нервной системы & 41,2 & 3,1 & 49,0 & 2,7 & 38,4 & 3,2 & 31,6 & 2,0 \\
\hline $\begin{array}{l}\text { Болезни глаза и его придаточного } \\
\text { аппарата }\end{array}$ & 74,4 & 5,6 & 101,0 & 5,6 & 65,6 & 5,4 & 117,0 & 7,3 \\
\hline Болезни уха и сосцевидного отростка & 31,5 & 2,4 & 48,3 & 2,7 & 27,6 & 2,3 & 40,0 & 2,5 \\
\hline Болезни системы кровообращения & 174,8 & 13,1 & 13,9 & 0,8 & 212,3 & 17,6 & 423,8 & 26,4 \\
\hline Болезни органов дыхания & 381,9 & 28,7 & 1096,3 & 60,3 & 218,3 & 18,1 & 207,4 & 12,9 \\
\hline Болезни органов пищеварения & 85,0 & 6,4 & 88,0 & 4,8 & 83,5 & 6,9 & 106,3 & 6,6 \\
\hline Болезни кожи и подкожной клетчатки & 61,7 & 4,6 & 90,5 & 5,0 & 53,8 & 4,5 & 53,4 & 3,3 \\
\hline $\begin{array}{l}\text { Болезни костно-мышечной системы и } \\
\text { соединительной ткани }\end{array}$ & 90,7 & 6,8 & 48,1 & 2,6 & 99,0 & 8,2 & 146,1 & 9,1 \\
\hline Болезни мочеполовой системы & 82,0 & 6,2 & 32,7 & 1,8 & 92,1 & 7,6 & 89,8 & 5,6 \\
\hline Внешние причины & 87,6 & 6,6 & 90,4 & 5,0 & 82,9 & 6,9 & 70,9 & 4,4 \\
\hline
\end{tabular}


болевания, хронические заболевания впервые выявленные и ранее известные) всего населения составляет 1331 на 1000 населения, при этом максимальные показатели регистрируются у детей от 0-14 лет $-1816,8 \%$ и лиц старше трудоспособного возраста $-1605 \%$.

В 2018 году общая заболеваемость населения в Московской области по сравнению с 2017 годом возросла почти на $2 \%$ (Российская Федерация $-1634,3 \%$, рост на $1 \%$, в ЦФО $-1471,8$, рост на $1,6 \%)$.

Для детей 0-14 лет характерны наиболее высокие уровни инфекционных и паразитарных болезней $-60,7 \%$, болезней уха и сосцевидного отростка $-48,3 \%$, болезней органов дыхания $1096,3 \%$, болезней нервной системы $-49,0 \%$ и врожденные аномалии - 18,7\% по сравнению с другими возрастными группами [1].

У подростков (15-17 лет) наиболее высокими показателями являются психические расстройства и расстройства поведения - 49,4\% и болезни нервной системы $-807,2 \%$, а также болезни глаза и его придаточного аппарата - 181,2\%, болезни кожи и подкожной клетчатки $-122,6 \%$, травмы и отравления $-220,8 \%$ [2].

Наивысшие показатели заболеваемости болезнями эндокринной системы - 144,1\%, новообразованиями - 108,2\%, болезнями системы кровообращения - 423,8\%, болезнями костномышечной системы и соединительной ткани $146,1 \%$ зарегистрированы у лиц старше трудоспособного возраста.

В структуре заболеваемости у детей основное место занимают болезни органов дыхания $-60,3 \%$, далее следуют болезни глаза и его придаточного аппарата $-5,6 \%$, болезни кожи и подкожной клетчатки - 5\% [2].

У подростков также лидирующая позиция в структуре общей заболеваемости приходится на болезни органов дыхания, которые составляют $43,4 \%$, второе место занимают травмы и отравления $-10,7 \%$, далее следуют болезни глаза и его придаточного аппарата $-8,8 \%$.

Для взрослого населения основная доля 51,5\% от всех заболеваний приходится на болезни органов дыхания - 18,1\% и системы кровообращения - $17,6 \%$, болезни костно-мышечной системы $-8,2 \%$ и болезни мочеполовой системы $-7,6 \%$ [10].

У лиц старше трудоспособного возраста первое место занимают болезни системы кровообращения $-26,4 \%$, второе место приходится на болезни органов дыхания - 12,9\%, третье на болезни костно-мышечной системы и соединительной ткани $-9,1 \%$, болезни эндокринной системы, расстройства питания и нарушения обмена веществ - 9\%, данный класс болезней формируется в основном за счет сахарного диабета.

У населения Московской области в целом зарегистрированы высокие показатели заболеваемости сахарным диабетом, которые составили в 2018 году 32 случая на 1000 населения, однако эти показатели на 6,6\% меньше, чем в ЦФО и на $3,4 \%$ меньше, чем в Российской Федерации. Рост общей заболеваемости сахарным диабетом с 2014 по 2018 годы составил почти 7\% [6, С. 36].

В Московской области создано региональных сосудистых центров - 10, первичных сосудистых отделений -12 .

По данным 2018 года отмечена низкая доля охвата диспансерным наблюдением пациентов с ИБС - 59,2\%. Данное значение ниже среднероссийского на $8,2 \%$ (Российская Федерация $64,5 \%)$.

Отмечена низкая доля пациентов с ОКС, госпитализированных в профильные отделения (РСЦ и ПСО) - 76\%. Данное значение ниже среднероссийского на 9,3\% (Российская Федерация $83,8 \%)$.

$40 \%$ - доля пациентов с крайней степенью нарушений мозгового кровообращения, госпитализированных с отделения для лечения больных с региональными сосудистыми центрами и первичными сосудистыми отделениями (ОНМК) в первые 4,5 часа с момента начала заболевания с тем условием, что рекомендованное значение - не менее $40 \%$ [2]. Значение показателя демонстрирует положительную динамику относительно аналогичного периода прошлого года - показатель вырос на 10,5\%.

Отмечено достижение рекомендованного значения показателя доли больных с острым коронарным синдромом с подъемом сегмента ST, которым выполнен тромболизис (на догоспитальном и госпитальном этапах) $-25,2 \%$ (рекомендованное значение - не менее 25\%). Положительная динамика показателя относительно аналогичного периода 2017 года рост на 37\%.

Достижение рекомендованного значения доли ангиопластик коронарных артерий, проведенных больным с острым коронарным синдромом, к общему числу выбывших больных, перенесших острый коронарный синдром - 48,3\% (рекомендованное значение - не менее 30\%). 
Наблюдается положительная динамика показателя относительно аналогичного периода прошлого года - показатель вырос на 26,1\%.

Число ангиопластик коронарных артерий, проведенных пациентам с острым коронарным синдромом в 2018 г. составило 9169, при минимально необходимом значении - 5692. Дополнительная потребность в выполнении ангиопластик отсутствует [12].

Отмечено невыполнение рекомендованного значения показателя доли больных с ишемическим инсультом, которым выполнен системный тромболизис - 4\% (рекомендованное значение - не менее 5\%). Положительная динамика показателя относительно аналогичного периода прошлого года - показатель вырос на 110,5\%.

Отмечена высокая летальность пациентов с ИМ в стационарах региона - 13,1\%. Данное значение выше среднероссийского на 4\% (Российская Федерация - 12,6\%).

Рекомендованное значение показателя доли больных с острым коронарным синдромом умерших в первые сутки от числа всех умерших с острым коронарным синдромом за период госпитализации не достигнуто в 2018 г.- 37,5\% (рекомендованное значение - не более 25\%). Отмечена положительная динамика показателя относительно аналогичного периода прошлого года - показатель снизился на 0,8\% [9].

Отмечена высокая летальность пациентов с острыми нарушениями мозгового кровообращения - 20,3\%. Данное значение выше среднероссийского на 20,8\% (Российская Федерация $16,8 \%)$.

Доля пациентов с острыми нарушениями мозгового кровообращения, умерших на догоспитальном этапе составляет 6,3\%. Данное значение ниже среднероссийского на 47,1\% (Российская Федерация - 11,9\%).

20,3\% - доля умерших больных с ишемическим и геморрагическим инсультом в стационарах региона от общего количества выбывших больных с ишемическим и геморрагическим инсультом с тем условием, что рекомендованное значение - не более 20\% [2]. Наблюдается положительная динамика показателя относительно аналогичного периода 2017 года - показатель снизился на $14 \%$.

Неудовлетворительные итоги по отдельным управляемым заболеваниям - системы кровообращения, органов пищеварения, реабилитации и лечения $3 \mathrm{HO}$, высокой смертности от отрав- лений алкоголем свидетельствуют о нереализованном потенциале первичного звена здравоохранения в достижении позитивных результатов по данным показателям.

Медицинская помощь населению в Московской области в 2019 году оказывалась в 122 больницах, 27 диспансерах, 23 самостоятельных амбулаторно-поликлинических учреждениях, 682 амбулаторно-поликлинических подразделениях, которые также включены в состав больничных учреждений, 30 стоматологических поликлиниках, 507 фельдшерско-акушерских пунктах, 2 врачебных здравпунктах, 15 фельдшерских пунктах [9].

В 2019 году в Московской области работали 24926 врачей и 48884 человека среднего медицинского персонала.

Обеспеченность населения врачами в Московской области ниже общероссийского уровня и по федеральному округу в целом, и составила в 2019 году 32,8 на 10 тыс. населения, рост на 3,5\% (Российская Федерация - 37,6, рост на 0,5\%, ЦФО - 37,9, рост на 1,3\%). Обеспеченность населения средним медицинским персоналом также ниже общероссийского уровня и по округу в целом, и составила в 2019 году 67,4 на 10 тыс. населения, снижение на 0,2\% (Российская Федерация - 85,8 на 10 тыс. населения снижение на 0,6\%, ЦФО - 78,7 на 10 тыс. населения снижение на 0,6\%), данные отражены в таблице 2 .

Самая низкая укомплектованность в Московской области - это младший медицинский персонал - 83\% и врачи - 85\%, среди этих категорий медицинский работников и самый высокий коэффициент совместительства, данные представлены в таблице 3.

Коечный фонд стационаров в Московской области в 2019 году составил 48685 коек, в 2018 году - 49177 коек. Обеспеченность населения койками снизилась на $0,9 \%$ и составила 64,1 на 10 тыс. населения (Российская Федерация - 70,2, снижение на 1,4\%, ЦФО - 65,7, снижение на $1,4 \%)$. Число пролеченных в стационарах Московской области составляет 1,4 млн. пациентов (в Российской Федерации - 29 млн.) и выполнено 225 тыс. операций.

Отмечается тенденция снижения средней длительности пребывания больного на койке, которая в 2019 году в Московской области составила - 10,3 дня (Российская Федерация - 10,8 дней).

Число вызовов скорой медицинской помощи 
Таблица 2. Динамика численности врачей и среднего медицинского персонала и их обеспеченность (на 10 тыс. населения) [9].

\begin{tabular}{|l|c|c|c|c|c|c|}
\hline \multicolumn{1}{|c|}{ Показатели } & \multicolumn{2}{|c|}{ Российская Федерация } & \multicolumn{3}{c|}{ Московская область } \\
\cline { 2 - 8 } & 2017 & 2018 & 2019 & 2017 & 2018 & 2019 \\
\hline $\begin{array}{l}\text { Всего среднего медицинского персонала, чис- } \\
\text { ленность }\end{array}$ & 1266181 & 1224215 & 1214893 & 51215 & 48663 & 48884 \\
\hline $\begin{array}{l}\text { обеспеченность средним медперсоналом на 10 } \\
\text { тыс. населения }\end{array}$ & 86,2 & 83,3 & 85,8 & 68,3 & 64,9 & 67,4 \\
\hline Всего врачей, численность & 548414 & 548818 & 551473 & 23963 & 24085 & 24926 \\
\hline обеспеченность врачами на 10 тыс.населения & 37,3 & 37,4 & 37,6 & 31,9 & 32,1 & 32,8 \\
\hline Врачи общей практики (семейные), всего & 11046 & 11584 & 11358 & 353 & 345 & 346 \\
\hline обеспеченность врачами на 10 тыс. населения & 0,8 & 0,8 & 0,8 & 0,5 & 0,5 & 0,5 \\
\hline
\end{tabular}

Таблица 3. Укомплектованность (в \%) и коэффициент совместительства медицинских работников в Российской Федерации и Московской области, 2019 год

\begin{tabular}{|c|c|c|c|c|}
\hline \multirow{2}{*}{ Медицинские работники } & \multicolumn{2}{|c|}{ Российская Федерация } & \multicolumn{2}{|c|}{ Московская область. } \\
\cline { 2 - 5 } & $\begin{array}{c}\text { Укомплектован- } \\
\text { ность }\end{array}$ & $\begin{array}{c}\text { Коэффициент } \\
\text { совместитель- } \\
\text { ства }\end{array}$ & $\begin{array}{c}\text { Укомплектован- } \\
\text { ность }\end{array}$ & $\begin{array}{c}\text { Коэффициент } \\
\text { совместитель- } \\
\text { ства }\end{array}$ \\
\hline \multicolumn{1}{|c|}{ Врачи } & 84 & 1,3 & 85 & 1,4 \\
\hline участковые педиатры & 92 & 1,1 & 93 & 1,1 \\
\hline участковые терапевты & 84 & 1,1 & 89 & 1,1 \\
\hline Врачи общей практики (семейные) & 83 & 1,1 & 89 & 1,25 \\
\hline Средний медицинский персонал & 88 & 1,2 & 88 & 1,4 \\
\hline Младший медицинский персонал & 85 & 1,3 & 83 & 1,4 \\
\hline
\end{tabular}

в Московской области в 2019 году увеличилось на 1,6\%, с 302,4 до 307,1 на 1000 населения (Российская Федерация - 300,6, рост на 0,3\%, ЦФО $308,2$, рост на $1,0 \%)$.

Доля выездов бригад скорой медицинской помощи со временем доезда до больного менее 20 минут в 2019 году составила $88,7 \%$, от 21 до 40 минут 8,3\%, до 60 минут 2,5\%, более часа $0,5 \%$ [16, C.4].

Проблемы с обеспеченностью врачами общей практики свидетельствуют о низком уровне развития этой службы в регионе, рост числа вызовов скорой медицинской помощи о неудовлетворительной работе первичного звена здравоохранения.

Нормативы объемов медицинской помощи в рамках Московской областной программы ОМС соответствуют федеральным показателям по всем условиям оказания медицинской помощи, несколько превышая установленные нормативы в условиях круглосуточного стационара и по высокотехнологичной медицинской помощи [8].

В соответствии с Методическими рекомендациями Минздрава России и ФФОМС по спо- собам оплаты медицинской помощи за счет средств ОМС в регионе были установлены следующие способы оплаты:

- для амбулаторно - поликлинической помощи - по подушевому нормативу финансирования на прикрепившихся лиц в сочетании с оплатой за единицу объема медицинской помощи;

- для стационарных условий, включая дневной стационар - за законченный случай лечения заболеваний, включенных в соответствующую группу КСГ/КПГ;

- для скорой медицинской помощи - по подушевому нормативу в сочетании за вызов скорой медицинской помощи.

В 2018 году в отдельных медицинских организациях области была реализована модель оплаты по подушевому финансированию на прикрепленное население, включая оплату по всем видам и условиям медицинской помощи с оценкой показателей результативности за выполнение согласованных объемов.

Особенности подушевого финансирования в Московской области: 
- подушевое финансирование не основано на принципах фондодержания и взаиморасчетах между медицинскими организациями;

- в подушевое финансирование не входят профилактические мероприятия, диспансеризация, отдельные услуги - КТ, МРТ, скрининг некоторых заболеваний, оплата которых осуществляется за объем оказанных услуг.

Размер базового подушевого норматива финансирования амбулаторно-поликлинической помощи сократился с 215 руб. в 2018 году до 152 руб. к 2020 году, в связи с дополнительным исключением посещений «узких» специалистов из подушевого норматива и расширением перечня отдельных услуг, оплачиваемых по объемному способу оплаты - УЗИ, биопсия, анестезия.

- в модели подушевого финансирования ПМСП не учитываются особенности функционирования ОВП, т.е. вся амбулаторная помощь оплачивается по одним принципам;

- отсутствует модель конечных результатов деятельности амбулаторно-поликлинической службы;

- в связи с реорганизацией сети учреждений здравоохранения в виде слияния медицинских организаций в одно юридическое лицо на уровне муниципального образования и ликвидацией самостоятельных медицинских организаций, оказывающих первичную медико-санитарную помощь, подушевое финансирование амбула- торной помощи входило в состав общего финансирования деятельности всей медицинской организации [17].

Особенности оплаты по КСГ:

- оплата осуществляется в соответствии с методическими рекомендациями Минздрава России и ФФОМС в рамках согласованных объемов медицинской помощи;

- при условии подушевого финансирования деятельности медицинской организации на весь объем деятельности, включая стационарную помощь, оплата осуществлялась в рамках утвержденного объема финансирования через коэффициент приведения фактических объемов к плановым и ежеквартальной оценкой деятельности медицинской организации.

В региональной модели оплаты медицинской помощи амбулаторная служба заинтересована в количестве прикрепленного населения и наращивании объемов услуг профилактики (диспансеризация) и диагностики (КТ, МРТ, ПЭТ), как наиболее дорогостоящих, дополняющих подушевое финансирование. Объемы компьютерной томографии за год в государственных медицинских организациях возросли более чем в 2 раза, что проиллюстрировано на рисунке 1.

Качественные показатели оказания медицинской помощи и конечные результаты деятельности медицинских организаций не являются критериями в распределении объемов и

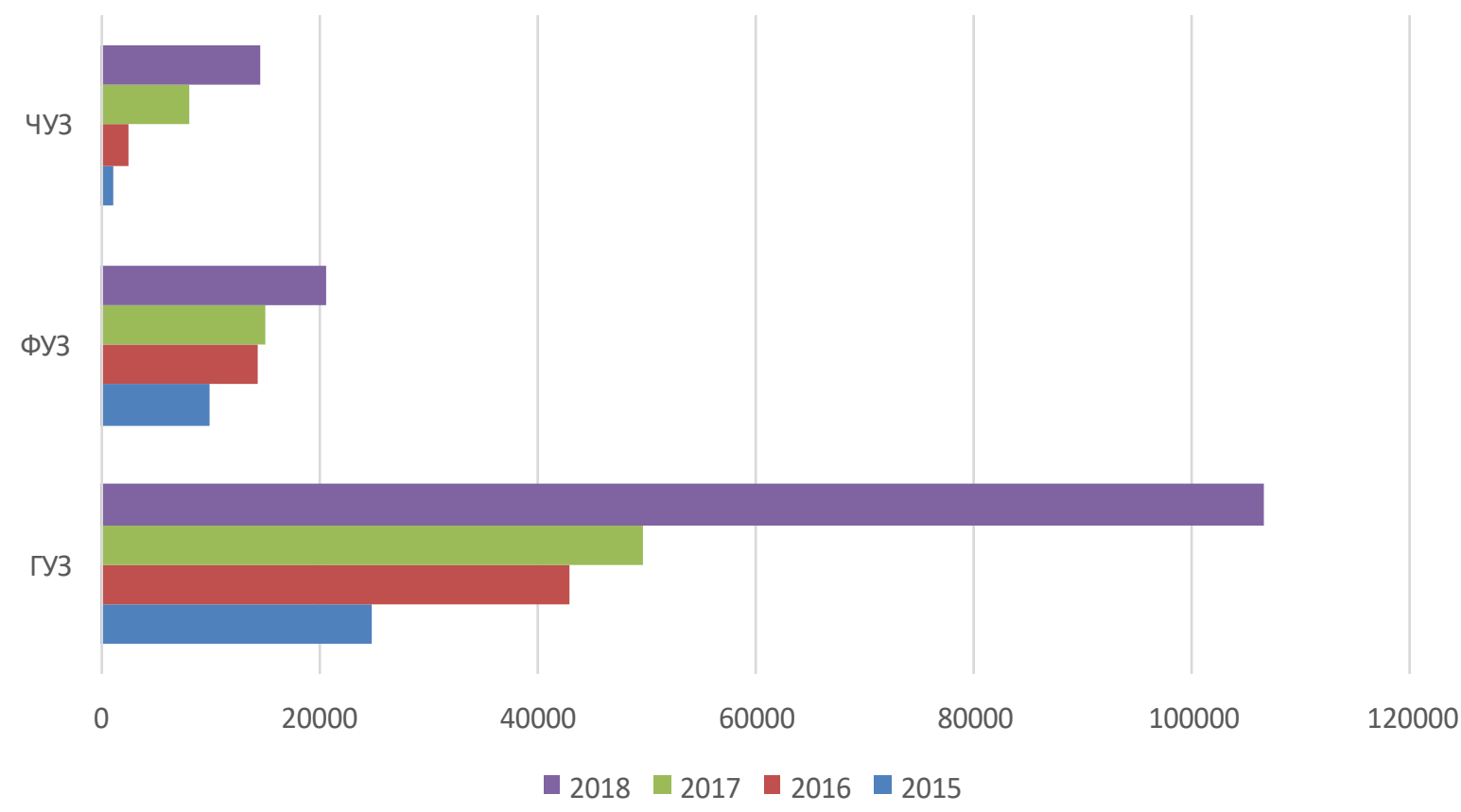

Рисунок 1. Показатели изменения объемов КТ в рамках Московской областной программы ОМС за 2015-2018 гг. 
уровне оплаты оказанных медицинских услуг.

В стационарных условиях главным показателем эффективной работы подразделений является коэффициент затратоемкости КСГ, он тем выше, чем тяжелее пациент и сложнее технология его лечения.

Отсутствие модели конечных результатов деятельности медицинских организаций и системы взаиморасчетов полностью исключили взаимосвязь между поликлиникой и стационаром. Финансовое обеспечение стационарной помощи зависит от количества распределенных объемов и высокого коэффициента затратоемкости КСГ, для достижения которого не редко используются приписки по данным экспертизы [5].

Модели планирования объемов и оплаты медицинской помощи в условиях свободного выбора медицинской организации застрахованными и достаточным уровнем развития конкуренции в сфере здравоохранения должны пройти дополнительную настройку, прежде всего направленную на взаимодействие амбулаторного и стационарного звена, как единого цикла оказания медицинской помощи пациенту, в основе которого лежат конечные результаты не только лечения заболеваний, но и профилактические мероприятия [13].

На сегодняшний день мы имеем модернизированную реформами советскую инфраструктуру медицинских организаций и квазирыночные механизмы планирования и оплаты медицинской помощи. Данное сочетание позволяет содержать неэффективную структуру медицинских организаций, за счет выполнения и перевыполнения ими объемных показателей деятельности.

Анализ объемов потребления медицинской помощи в разрезе условий ее оказания и половозрастной структуры по данным реестров счетов медицинских организаций, реализующих Московскую областную программу ОМС, показывает отсутствие заинтересованности медицинских организаций, оказывающих амбулаторную помощь в адекватной профилактике заболеваний, высокие уровни оказания специализированной, в том числе высокотехнологичной, медицинской помощи [14].

Интегральным показателем эффективности работы системы здравоохранения является мнение граждан по результатам проведенных социологических опросов о качестве оказываемых медицинских услуг. Общее количество от- ветов по причинам неудовлетворенности качеством медицинского обслуживания в условиях поликлиники, имеющих отрицательный тренд, составили 65\%, против 35\% позитивных. Общее количество причин неудовлетворенности пациентов условиями оказания стационарной помощи с отрицательным трендом по данным социологических опросов 2012-2019 гг. составляет 30\%, против 70\%, имеющих позитивную динамику [11].

Сохраняющийся дефицит врачей первичного звена привел в 2019 году к росту ограничений при записи на прием к специалистам. Проводимые реформы не привели к уменьшению платных медицинских услуг в поликлинике, остаются трудности с получением льготных лекарств, в стационаре остаются нерешенными вопросы бесплатного лекарственного обеспечения, качественного питания, а также соблюдения установленных программой государственных гарантий сроков госпитализации.

Анализ фактических результатов функционирования системы ОМС выявил нерешенные проблемы действующей отечественной страховой модели здравоохранения - низкая удовлетворенность населения оказанием первичной медико-санитарной помощи, высокий уровень неформальных платежей, неудовлетворительные целевые показатели заболеваемости и смертности населения, установленные национальными программами развития здравоохранения. На региональном уровне в силу приоритетов развития стационарной помощи выявляются проблемы с доступностью оказания медицинской помощи в первичном звене здравоохранения.

Для повышения эффективности работы системы здравоохранения нужны механизмы тонкой настройки действующих методов планирования, организации и оплаты медицинской помощи, направленные на конечные результаты деятельности.

Для внедрения механизмов экономического управления результатами работы первичного звена здравоохранения необходимо реализовать модель подушевого финансирования с элементами фондодержания с оплатой за достижение показателей результативности деятельности медицинских организаций, оказывающих первичную медико-санитарную помощь прикрепленному населению. 


\section{Библиографический список}

1. Бантьева М.Н., Маношкина Е.М. Тенденции заболеваемости и динамика хронизации патологии у детей 0-14 лет в Российской Федерации//Социальные аспекты здоровья населения. № 11. 2019.

2. Голубев Н.А., Огрызко Е.В., Шелепова Е. А. Заболеваемость детей болезнями эндокринной, расстройствами питания и нарушениями обмена веществ//Современные проблемы здравоохранения и медицинской статистики. № 3, 2019.

3. Гехт И.А., АртемьеваГ.Б. Когда фондодержание необходимо // Менеджер здравоохранения.- 2014.№ $10 .-$ С.47-52.

4. Дуганов М.Д. Оценка эффективности расходов на здравоохранение на региональном и муниципальном уровнях / М: ИЭПП,-2007.- 112 с.

5. Лудупова Е. Ю. Научно-организационные принципы построения территориальной системы управления качеством медицинской деятельности: диссертация ... доктора медицинских наук.- М.: 2019. 295 с.

6. Мадьянова В.В., Арестова А. А., Винокуров В. Г., Алленов А. М. Современное состояние сферы предоставления платных медицинских услуг в бюджетных учреждениях амбулаторно-поликлинической сети Москвы // Проблемы стандартизации в здравоохранении. - 2016. - № 5-6.- С. 36-40.

7. Об итогах работы Министерства здравоохранения Российской Федерации//Справочник заведующего Кдл. № 6, 2015. C. 41-76 https://m.e.zavkdl.ru/?mid=24127 [дата обращения: 18.01.2021].

8. Постановление Правительства Российской Федерации от 07.12.2019 г. О Программе государственных гарантий бесплатного оказания гражданам медицинской помощи на 2020 год и на плановый период 2021 и 2022 годов https://www.mgfoms.ru/documents/23582 [дата обращения: 20.01.2021].

9. Постановление Правительства Московской области от 27.12.2019 № 1047/45 “О Московской областной программе государственных гарантий бесплатного оказания гражданам медицинской помощи на 2020 год и на плановый период 2021 и 2022 годов” http://static.government.ru/media/files/KeKsCYhldsEbwaStnPQEqpuB AZMbobzg.pdf [дата обращения: 21.01.2021].

10. Приказ Министерства здравоохранения РФ от 15.01.2020 № 8 «Об утверждении Стратегии формирования здорового образа жизни населения, профилактики и контроля неинфекционных заболеваний на период до 2025 года». Доступно по ссылке: https://www.garant.ru/products/ipo/prime/doc/73421912/ [дата обращения: 21.01.2021].

11. Приказ Министерства здравоохранения РФ от 10 ноября 2017 г. N 905 “Об утверждении методики оценки эффективности государственной программы Российской Федерации “Развитие здравоохранения”. http:// www.consultant.ru [дата обращения: 21.01.2021].

12. Улумбекова Г.Э.Здравоохранение России. Что надо делать: научное обоснование “Стратегии развития здравоохранения РФ до 2020 года” [Электронный ресурс] / Улумбекова Г. Э. - М.: ГЭОТАР-Медиа, 2010.

13. Хальфин Р.А., Муравьев Д. Н., Какорина Е.П., Розалиева Ю.Ю., Кришталева Т. И. Анализ результатов внедрения подушевой оплаты с элементами фондодержания в Российской Федерации/Проблемы социальной гигиены, здравоохранения и истории медицины. 2020. Т.28 № 6. С.1333-1338

14. Хальфин Р.А., Какорина Е. П., Мадьянова В. В., Игнатьева М. В. Оценка эффективности деятельности органов государственной власти в сфере здравоохранения Российской Федерации / М.,- 2013.

15. Ходакова О.В. Механизмы правового регулирования качества оказываемой медицинской помощи//Забайкальский медицинский вестник. № 1. 2013. С. 193-205.

16. Шляфер С.И. Анализ показателей работы скорой медицинской помощи в России//Скорая медицинская помощь. № 2, 2019. С.4-13.

17. Шишкин С.В., Шейман И. М., Потапчик О.Ф., Понкратова О. Ф. Анализ состояния страховой медицины в России и перспектив ее развития / НИУ «Высшая школа экономики».- 2019. 